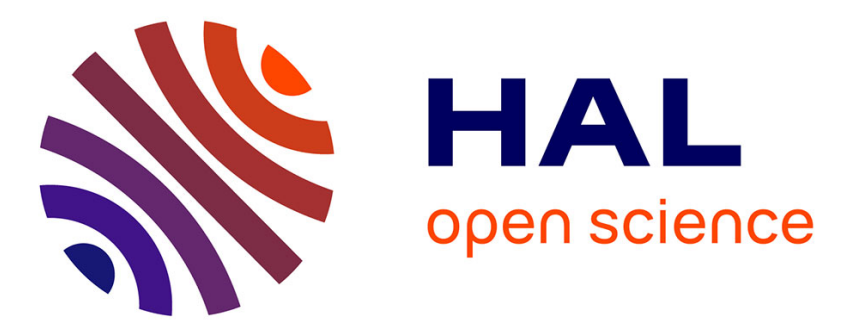

\title{
Determination of Polycyclic Aromatic Hydrocarbons in Urban Runoff Samples from the "Le Marais" Experimental Catchment in Paris Centre
}

\author{
Ana Gonzalez, Régis Moilleron, Ghassan Chebbo, Daniel R. Thevenot
}

\section{To cite this version:}

Ana Gonzalez, Régis Moilleron, Ghassan Chebbo, Daniel R. Thevenot. Determination of Polycyclic Aromatic Hydrocarbons in Urban Runoff Samples from the "Le Marais" Experimental Catchment in Paris Centre. Polycyclic Aromatic Compounds, 2000, 20 (1-4), pp.1-19. 10.1080/10406630008034772 . hal-01179901

\author{
HAL Id: hal-01179901 \\ https://hal.science/hal-01179901
}

Submitted on 23 Jul 2015

HAL is a multi-disciplinary open access archive for the deposit and dissemination of scientific research documents, whether they are published or not. The documents may come from teaching and research institutions in France or abroad, or from public or private research centers.
L'archive ouverte pluridisciplinaire HAL, est destinée au dépôt et à la diffusion de documents scientifiques de niveau recherche, publiés ou non, émanant des établissements d'enseignement et de recherche français ou étrangers, des laboratoires publics ou privés. 


\author{
DETERMINATION OF POLYCYCLIC AROMATIC \\ HYDROCARBONS IN URBAN RUNOFF SAMPLES FROM THE \\ "LE MARAIS" EXPERIMENTAL CATCHMENT IN PARIS \\ CENTRE.
}
Ana GONZALEZ ${ }^{\mathrm{a}}$, Régis MOILLERON ${ }^{\mathrm{a}}$, Ghassan $\mathrm{CHEBBO}^{\mathrm{b}}$ and Daniel R. THÉVENOT ${ }^{\mathrm{a}}$

(a) Cereve, Université Paris XII-Val de Marne, Faculté de Sciences et Technologie, 61 Avenue du Général de Gaulle, 94010 Créteil Cedex, France; (b) Cereve, ENPC, Cité Descartes, 6-8 Avenue Blaise Pascal, Champs sur Marne, 77455 Marne la Vallée Cedex 2, France.

Corresponding author : Régis Moilleron, Cereve, Université Paris XIIVal de Marne, Faculté des Sciences et Technologie, 61 Avenue du Général de Gaulle, 94010 Créteil Cedex, France (phone : 33-1 451716 22, fax : 33-145171627, e-mail : Moilleron@univ-paris12.fr) 


\section{ABSTRACT}

A study for assessing the sources and fate of pollutants during their transport within urban catchment was carried out in the central Paris district, "Le Marais". 16 polycyclic aromatic hydrocarbons were assessed, according to the EPA list, in different types of runoff from a town centre and wet weather waste waters at the outlet of the catchment. PAHs were found predominantly in particulate phase whatever the sample. The median levels found in the different runoffs ranged from below the detection limit (i.e. $1 \mathrm{ng} . \mathrm{L}^{-1}$ ) to $215 \mathrm{ng} . \mathrm{L}^{-1}$. For the combined sewer outlet, it was 204 ng. $\mathrm{L}^{-1}$. Phenanthrene, anthracene, fluoranthene and pyrene were the most observed compounds. The PAH runoff contents were compared to the combined sewer outlet during wet weather and the total atmospheric fallout. The results show the major role of the atmosphere as a pollution vector as well as the high contribution of the sewer network.

Keywords PAH; urban surfaces; urban runoff; combined sewer; experimental catchment.

\section{INTRODUCTION}

The importance of urban storm water runoff pollution loads and their acute impact on receiving waters (river, lake or sea) have been largely 
demonstrated $[1,2]$. Today, reduction of urban storm water pollution has become a major concern for many municipalities both in order to recover the quality of the receiving water bodies and in order to meet the new European regulations.

However, the elaboration of urban storm water management strategies requires improved knowledge on the characteristics, the origins and the transport of pollution during a rain event at different levels of an urban catchment. These are the three objectives of an important research program launched by the CEREVE (Water, City, Environment Education and Research Centre, Paris) in 1994, entitled "Production and transport of wet weather pollution in urban catchments". This research takes its stand on an experimental urban catchment (situated in the "Le Marais" district in central Paris) which equipment makes it possible to follow up the quality of wet weather flows from the entry up to the exit of the combined sewer network. Many parameters have been studied such as suspended solids, volatile solids, chemical oxygen demand, biochemical oxygen demand, heavy metals and hydrocarbons.

This paper will focus on polycyclic aromatic hydrocarbons (PAHs). PAHs are formed by the incomplete combustion of organic matter particularly fossil fuels. 16 PAHs were assessed according to the US Environmental Protection Agency (EPA) priority pollutants list. They are of toxicological concern because they are precursors of cancer-causing metabolites $[3,4]$. Moreover, they are ubiquitous in the urban environment from the atmospheric up to the sewer compartments. 
Hence, our results are presented to emphasise the differences observed in terms of concentration and occurrence of PAHs in samples collected in the "Le Marais" experimental urban catchment. When possible, a comparison, based on the distribution of individual PAHs, has been established with available data to enable the identification of probable sources. Two approaches were used. Firstly, the urban runoffs were investigated to characterise the sewer entries. Then, the role of the sewer and the total atmospheric fallout were studied to evaluate their contribution to the $\mathrm{PAH}$ pollution.

\section{MATERIAL AND METHODS}

\section{$\underline{\text { Sampling sites and equipment }}$}

"Le Marais" catchment covers an area of 42 hectares (ha) in an old residential district, with small businesses and almost no industrial activities. It is situated in central Paris (France). It is densely populated (295 inhabitants.ha ${ }^{-1}$ ) and is impervious at $90 \%$.

Within the catchment, three kinds of urban surfaces are present, leading to three different types of runoff: roofs cover $54.5 \%$ of the area, streets represent $23 \%$, the remaining $22.5 \%$ of the surface takes in courtyards, gardens and public areas. 


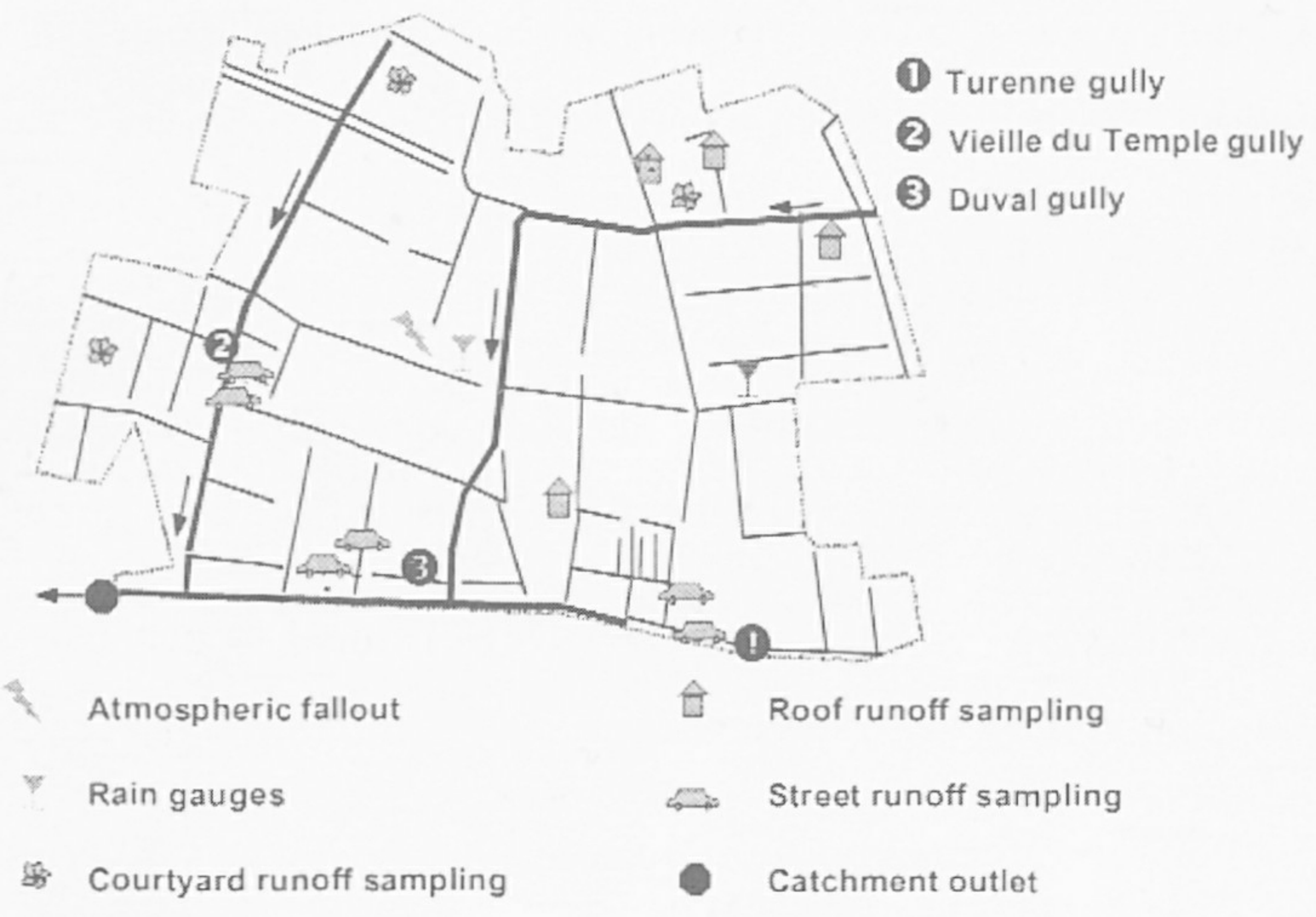

FIGURE 1 Sampling equipment at the "Le Marais" experimental urban catchment.

In order to characterise and quantify the pollution from the roof, street and courtyard runoffs, several sampling sites representative of the different types of land use were chosen as shown in Figure 1. Roof runoff was sampled from eleven roofs, representative of roof covering in the centre of Paris, i.e. interlocking clay tiles (ICT), flat clay tiles $(70 \%)+$ zinc sheet $(\mathrm{FCT})$, zinc sheets $(\mathrm{ZNT})$ and slate $(\mathrm{ST})$. Mean samples were taken in the roof gutters, during rain events, and collected in $100 \mathrm{~L}$ containers. Samples from three courtyards were collected with automatic samplers located inside the courtyard gullies. The courtyards were either paved with cobble stones (PAVC), concreted and planted with trees (CONC), and covered with grass and gravel (GRAC). Street runoffs from six different streets were collected in three gullies situated at street corners. Finally samples were collected at the combined sewer 
outlet during wet weather (CSOWW). A full description of the monitoring equipment is given elsewhere $[2,5]$.

Extraction and fractionation of PAHs.

All solvents were purified by distillation before use. To avoid contamination, the vessels used for sampling and analysis were treated as follows: glassware was cleaned with $5 \%$ Decon detergent (Prolabo) and water, rinsed with purified water (Milli-Ro 5 Plus, Millipore), heated in an oven at $450^{\circ} \mathrm{C}$ for $2 \mathrm{~h}$ to eliminate any traces of organic matter.

For runoff samples, an aliquot, typically $1 \mathrm{~L}$, was filtered by using a succession of pre-combusted and pre-extracted filters, from 2.7 $\mu \mathrm{m}$ (GF/F, Whatman) to $0.45 \mu \mathrm{m}$ (Millipore), in an all-glass filtration unit in order to separate dissolved and particulate phases. Particulate matter was dried to a constant weight at $40^{\circ} \mathrm{C}$. Before the extraction step of the procedure, internal perdeuterated standards were added in both phases, i.e. naphthalene $D_{8}$, phenanthrene $D_{10}$, pyrene $D_{10}$, benzo $[a]$ pyrene $\mathrm{D}_{12}$, benzo[ghi]perylene $\mathrm{D}_{12}$ (Euriso-top).

Dissolved PAH extraction. The filtrate samples were extracted by simple liquid-liquid extraction in a separation funnel using four successive $30 \mathrm{~mL}$ additions of methylene chloride (Merck). Before the last extraction, sample $\mathrm{pH}$ was adjusted to 2 using concentrated $\mathrm{H}_{2} \mathrm{SO}_{4}$ (Merck). Each of the four portions was shaken with the filtrate sample for $10 \mathrm{~min}$. The extracts were then combined, dried using $\mathrm{CaCl}_{2}$ (Prolabo) and concentrated to ca $5 \mathrm{~mL}$ using a rotary evaporator at room temperature under vacuum. This fraction was further evaporated to dryness under nitrogen flux (N5.0, Linde Gaz). Then $500 \mu \mathrm{L}$ of hexane (Merck) were added. This aliquot was fractionated into two 
fractions on a chromatographic column of $2 \mathrm{~g}$ of silica gel (Aldrich, 5.5 $\mathrm{mm}$ ID $\times 30 \mathrm{~cm}$ in length), by eluting with (i) $4 \mathrm{~mL}$ hexane and (ii) 6 $\mathrm{mL}$ methylene chloride-hexane $(80 / 20, \mathrm{v} / \mathrm{v})$ respectively. Aliphatic hydrocarbons were eluted with hexane (F1) and PAHs with the methylene chloride-hexane mixture (F2). Silica gel (Aldrich, 70-230 mesh, $60 \AA$ ) was preactivated at $450^{\circ} \mathrm{C}$ for $2 \mathrm{~h}$ and stored at $100^{\circ} \mathrm{C}$ prior to use. F1 and F2 were evaporated to $c a 50-100 \mu \mathrm{L}$ under nitrogen flux before quantification.

Particulate PAH extraction. Dried particulate matter was Soxhlet extracted for $24 \mathrm{~h}$ with a methylene chloride-methanol mixture (80/20, $\mathrm{v} / \mathrm{v})$. The extract was then concentrated to dryness under nitrogen flux as previously described. Then $500 \mu \mathrm{L}$ of hexane were added. This aliquot was eluted on a chromatographic column (5.5 mm ID x $30 \mathrm{~cm}$ in length), having, at the bottom, a layer of $500 \mathrm{mg}$ of activated copper (Aldrich, powder, $\sim 40$ mesh, $99.5 \%$ ) in order to desulphurise the sample and, at the top, a layer of $2 \mathrm{~g}$ of silica gel. Aliphatic hydrocarbons were eluted with $4 \mathrm{~mL}$ of hexane (F1) and PAHs with 6 $\mathrm{mL}$ of a methylene chloride-hexane mixture (80/20, v/v) (F2). F1 and F2 were evaporated to $c a 50-100 \mu \mathrm{L}$ under nitrogen flux prior to quantification. Copper was activated with $\mathrm{HCl}(7 \mathrm{~N})$, then washed with distilled water, acetone and hexane. Activated copper was kept in hexane at $4^{\circ} \mathrm{C}$ before use.

Quantification of PAHs.

PAHs were determined by GC-MS (GCD 1800 A, Hewlett Packard) using a PONA fused silica capillary column, $50 \mathrm{~m} \times 0.20 \mathrm{~mm}$ ID $\times 0.1$ $\mu \mathrm{m}$ film thickness (Hewlett Packard). The carrier gas was hydrogen at $1.0 \mathrm{~mL} \cdot \mathrm{min}^{-1}$. The injector temperature was set to $300^{\circ} \mathrm{C}$ and one $\mu 1$ 
injected. The column temperature was programmed from 70 to $300^{\circ} \mathrm{C}$ $\left(24 \mathrm{~min}\right.$ ) at $5^{\circ} \mathrm{C} \cdot \mathrm{min}^{-1}$. The detector temperature was held to $280^{\circ} \mathrm{C}$. $\mathrm{PAH}$ concentrations were determined using perdeuterated internal standards (naphthalene $\mathrm{D}_{8}$, phenanthrene $\mathrm{D}_{10}$, pyrene $\mathrm{D}_{10}$, benzo[a]pyrene $\mathrm{D}_{12}$, benzo[ghi]perylene $\mathrm{D}_{12}$ ) added previously [4]. Extraction and GC-MS quantification procedures were validated using a marine sediment certified sample (NIST 1941a); relative deviations as well as dispersion for triplicates were usually below $20 \%$ [6].

\section{RESULTS AND DISCUSSION}

13 out 16 PAHs were found in our samples at different occurrences. The 3-4 ring PAHs, such as phenanthrene, anthracene, fluoranthene and pyrene, were the most observed, they were almost present in every type of runoff and in the catchment outlet. The higher molecular weight compounds, such as benzo[ghi]perylene, $\operatorname{dibenz}[a, h]$ anthracene, indeno[1,2,3-cd]pyrene, were not present nor detected. PAHs were found predominantly in particulate phase in all cases whatever the sample. This could be due to the fact that the volume of sample available, in most cases $1 \mathrm{~L}$, was insufficient to reach detection limits allowed by liquid-liquid extraction [7]. Nevertheless, this is consistent with previous results $[3,8-10]$, which reported that hydrocarbons in urban runoff are associated to particulate matter at $90 \%$. While some authors $[11,12]$ are presenting mean values when dealing with $\mathrm{PAH}$ amount in urban runoff, we will comment our results on the basis of the median value, lower and upper deciles, respectively d50, d10 and d90 in tables and figures. Hence, the variability of the results collected 
during this research program is taken into account. Moreover data available concerning PAHs in urban runoff are somehow uncomplete, since either the number of samples or the standard deviation are missing.

\section{Levels and occurrence of PAHs in urban runoff.}

Roof runoff. While most median PAH concentrations, i.e. ICT, ST and ZNT, are within the range of $16-24 \mathrm{ng} \cdot \mathrm{L}^{-1}$, there is a significantly $2-3$ fold increase in the PAH amount of FCT (TABLE 1). The variability among the different roofs was smaller than the temporal variability. Depending on the roof type, the PAH concentration from one event to another is within the $0-700$ ng. $\mathrm{L}^{-1}$ range, whereas the PAH concentration was $16-50 \mathrm{ng} . \mathrm{L}^{-1}$ from one roof type to another. Our results are consistent with those of Förster [11, 13], who investigated runoff of five different roofs on the university campus of Bayreuth (Germany), in term of (i) concentration level, (ii) repartition between dissolved and particulate phases as well as (iii) temporal variability.

Phenanthrene, fluoranthene and pyrene were present in the four types of runoff. These three PAHs represented $85 \%$ of the total amount of PAHs for FCT, ST, ZNT. The ICT runoff is slightly different from the others, because the phenanthrene and pyrene proportions are weaker and the contribution of fluoranthene and higher molecular weight compounds to the total PAHs is more important. But it is difficult to know whether the difference is due to the roof material itself or its sorption properties. 
TABLE 1 Range of total PAH (ng. $\mathrm{L}^{-1}$ ) and particulate PAH (ng. $\mathrm{g}^{-1} \mathrm{dw}$ ) concentrations in the different types of runoff samples.

\begin{tabular}{lccccccc}
\hline & \multicolumn{3}{c}{ PAHs $\left(\mathrm{ng} . \mathrm{L}^{-1}\right)$} & \multicolumn{3}{c}{ PAHs $\left(\mathrm{ng} \cdot \mathrm{g}^{-1} \mathrm{dw}\right)$} \\
\hline Runoff & $\mathrm{n}$ & $\mathrm{d} 10$ & $\mathrm{~d} 50$ & $\mathrm{~d} 90$ & $\mathrm{~d} 10$ & $\mathrm{~d} 50$ & $\mathrm{~d} 90$ \\
\hline Roofs & & & & & & & \\
ICT & 19 & $<1$ & 24 & 724 & $<10$ & 800 & 11340 \\
FCT & 23 & $<1$ & 50 & 717 & $<10$ & 2000 & 10240 \\
ST & 42 & $<1$ & 16 & 487 & $<10$ & 450 & 14310 \\
ZNT & 33 & $<1$ & 22 & 687 & $<10$ & 600 & 14040 \\
\hline Courtyards & & & & & & & \\
CONC & 9 & $<1$ & $<1$ & 2235 & $<10$ & $<10$ & 24160 \\
PAVC & 6 & $<1$ & 54 & 671 & $<10$ & 2000 & 10240 \\
\hline Streets & & & & & & & \\
TUR & 11 & $<1$ & $<1$ & 375 & $<10$ & $<10$ & 8070 \\
DUV & 10 & $<1$ & 157 & 1382 & $<10$ & 1600 & 15270 \\
VDT & 11 & 82 & 215 & 1114 & 600 & 4300 & 19900 \\
\hline
\end{tabular}

Courtyard runoff. For the paved courtyard, the median value was 54 ng. $\mathrm{L}^{-1}$ and for the concrete one, the median value was below the detection limit, i.e. $1 \mathrm{ng} \cdot \mathrm{L}^{-1}$. The lack of data concerning courtyard runoff makes it difficult to compare our results to others. When the $\mathrm{PAH}$ distribution is assessed, phenanthrene and pyrene represented almost $90 \%$ of the total amount for both types of runoff. At a lesser extent, fluorene $(10 \%)$ was found only in PAVC, whereas anthracene $(13 \%)$ was only present in CONC.

Street runoff. The median of the total PAH concentrations measured in the different sample ranged from below $1 \mathrm{ng} . \mathrm{L}^{-1}$, for TUR sample, to $215 \mathrm{ng} . \mathrm{L}^{-1}$, for VDT, with an intermediate value for DUV (i. e. 157 ng. $\left.\mathrm{L}^{-1}\right)$. We could have expected an higher PAH concentration in 
Turenne gully due to the presence, in this street, of parking and an heavy to medium traffic, whereas in Vieille du Temple there is no parking and a low to medium traffic. Duval gully received runoff from streets with parking places and with a low traffic. Yet, it is not possible to establish any relation between the characteristics of the streets and the level of PAHs in the runoff as already noticed for some others parameters such as SS, COD and BOD5 [14]. But phenanthrene/anthracene ratios show values ranging from 1 to 5 in the gully samples, indicating that the street runoff mainly contains used motor oil adsorbed by street deposit $[10,15]$.

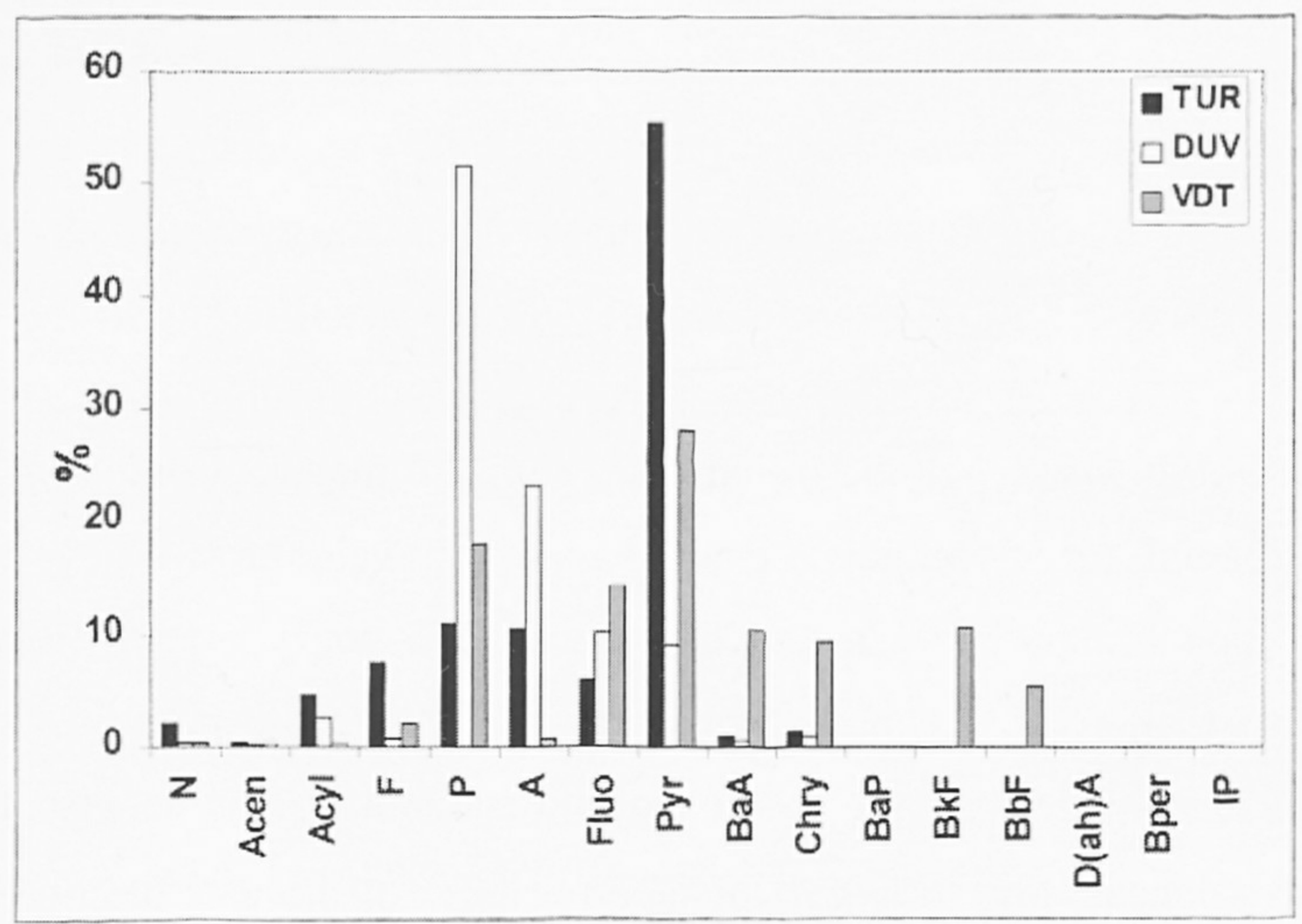

napththalene $=\mathrm{N}$, acenaphthene $=$ Acen, acenaphthylene $=$ Acyl, fluorene $=\mathrm{F}$, phenanthrene $=$ $\mathrm{P}$, anthracene $=\mathrm{A}$, fluoranthene $=$ Fluo, pyrene $=\mathrm{Pyr}$, benzo $[a]$ anthracene $=\mathrm{BaA}$, chrysene $=$ Chry, benzo[a]pyrene $=\mathrm{BaP}$, benzo $[k]$ fluoranthene $=\mathrm{BkF}$, benzo $[b]$ fluoranthene $=\mathrm{BbF}$, dibenz $[a, h]$ anthracene $=\mathrm{D}(\mathrm{ah}) \mathrm{A}$, benzo $[$ ghi $]$ perylene $=$ Bper, indeno $[1,2,3-c d]$ pyrene $=I P$.

FIGURE 2 Distribution of the individual particulate PAHs within the street runoff (expressed in \% of the total amount). 
Nevertheless, as shown by FIGURE 2, the distributions are different for the three gullies. The comparison of the PAH distributions revealed that the dominant PAHs were, for TUR and DUV, phenanthrene, anthracene, fluoranthene and pyrene, which accounted respectively for 83 and $94 \%$ of the total PAHs. For VDT, the PAH distribution was more homogeneous, 7 PAHs, i.e. phenanthrene, fluoranthene, pyrene, benzo $[a]$ anthracene, chrysene, benzo[ $k]$ fluoranthene averaging $91 \%$ of the total PAHs.

Comparison between runoff and wet weather PAH content at the combined sewer outlet.

To evaluate the runoff contribution to the PAH content at the combined sewer outlet, a "mean" PAH runoff (RUNOFF) concentration was calculated taking into account the different types of surfaces drained by each type of runoff. The results are presented in TABLE 2 as "Runoff". They were carried out for 9 out 19 rain events because the whole set of data was available those events. The calculation used was as follows:

$$
R=\frac{\sum_{i} R_{i} A_{i} C_{i} H}{\sum_{i} A_{i} C_{i} H}
$$

with $\mathrm{R}$ the "mean" PAH runoff concentration in ng. $\mathrm{L}^{-1}$, Ri the total $\mathrm{PAH}$ concentration in ng. $\mathrm{L}^{-1}$ for type i runoff, Ai the area drained by type i runoff in $\mathrm{m}^{2}$, Ci theoretical runoff coefficient for type i runoff and $\mathrm{H}$ the water height during the rain event in $\mathrm{m}$. 
TABLE 2 Range of total PAHs (ng. $\mathrm{L}^{-1}$ ) in combined sewer outlet samples during wet weather and "mean" runoff samples, (*) sum of the 6 PAHs taken into account by the French regulation.

\begin{tabular}{|c|c|c|c|c|}
\hline \multirow[t]{2}{*}{ samples } & & \multicolumn{3}{|c|}{ PAHs (ng.L -1 $^{-1}$} \\
\hline & $\mathrm{n}$ & $\mathrm{d} 10$ & $\mathrm{~d} 50$ & d90 \\
\hline CSOWW & 9 & 53 & 204 & 876 \\
\hline CSOWW* & 9 & $<1$ & 5.8 & 272 \\
\hline RUNOFF & 9 & 23 & 176 & 415 \\
\hline RUNOFF* & 9 & 2.8 & 14.8 & 87 \\
\hline
\end{tabular}

Samples collected at the catchment outlet during wet weather presented a PAH level of $204 \mathrm{ng} \cdot \mathrm{L}^{-1}$, which is slightly higher than the value of the "mean" runoff (176 ng. $\left.\mathrm{L}^{-1}\right)$ entering the combined sewer. This increase of the PAH content could be due to the domestic and industrial waste waters already present in the sewer during the rain event or/and the erosion of the sewer deposits. Indeed PAH levels have been measured in waste waters [16] arriving at various water treatment plants in the district of Paris in November 1998 during dry weather. Measurements, carried out on one single sample for each plant, showed a contamination ranging between 1840 and $3240 \mathrm{ng} \cdot \mathrm{L}^{-1}$. These values are ten to twenty times higher than our CSOWW results and demonstrate the high contamination of dry weather waste waters.

The PAH amount in RUNOFF and CSOWW may be compared to the French water quality standards for both surface and drinking waters. The French legislation takes into account six PAHs (fluoranthene, benzo $[k]$ fluoranthene, benzo $[b]$ fluoranthene, benzo $[a]$ pyrene, benzo[ghi]perylene), indeno[1,2,3-cd]pyrene) and recommends a total concentration below $200 \mathrm{ng} . \mathrm{L}^{-1}$ for drinking water 
(excepted for benzo[a]pyrene with a concentration below $10 \mathrm{ng} \cdot \mathrm{L}^{-1}$ ) and a maximum of $1000 \mathrm{ng} . \mathrm{L}^{-1}$ for surface waters used for drinking water production. The upper decile (d90) concentration for both RUNOFF* and CSOWW* are below the French regulation for such surface waters.

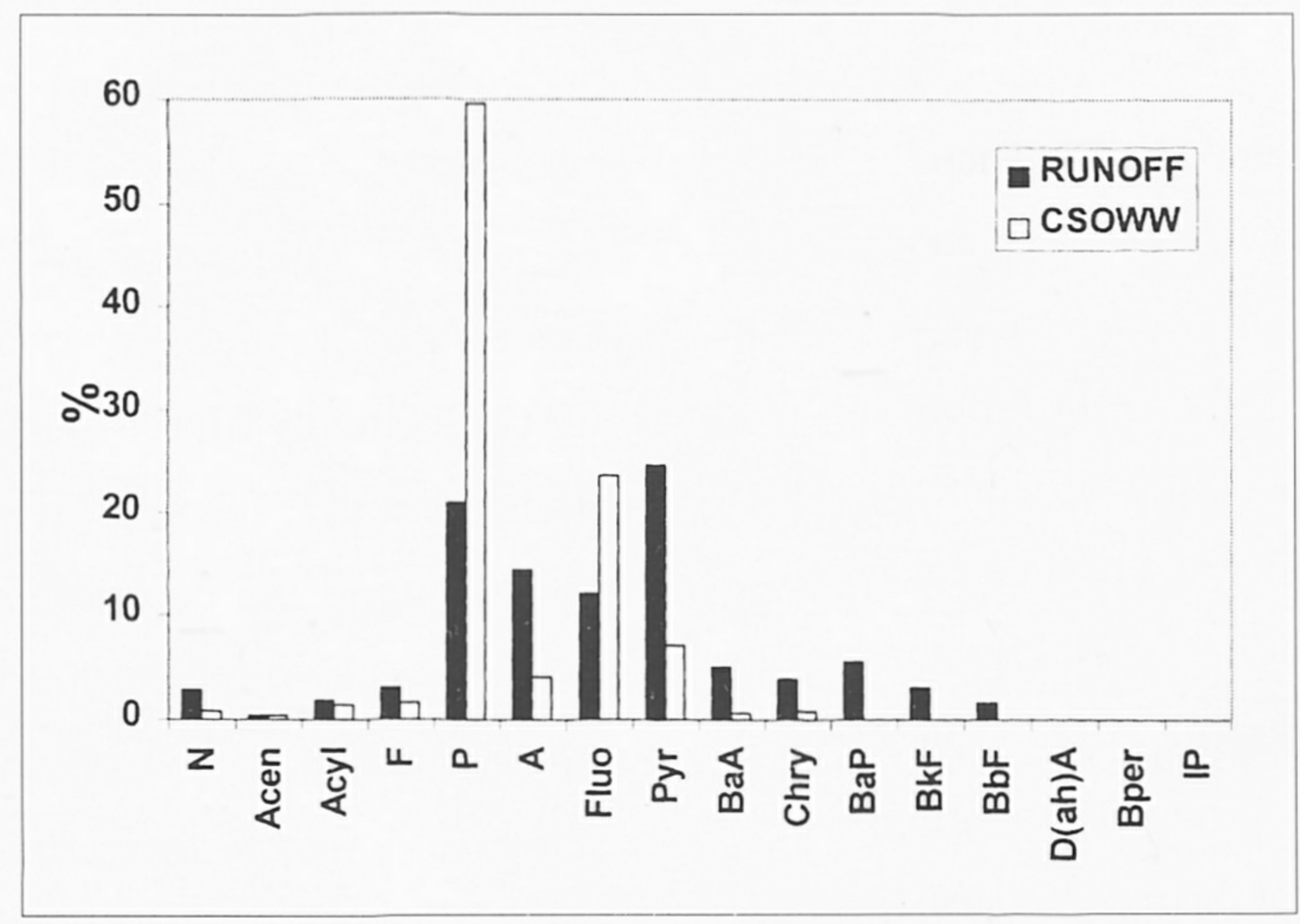

FIGURE 3 Comparison of the distribution of the individual particulate PAHs between wet weather samples at the catchment outlet and runoff samples (expressed in $\%$ of the total amount).

The comparison of the PAH distribution in RUNOFF and CSOWW samples showed that the major PAHs in both samples are phenanthrene, anthracene, fluoranthene and pyrene. They represent 94 and $72 \%$ for CSOWW and runoff respectively (FIGURE 3 ). In the runoff samples, higher molecular weight compounds were present. In comparison, dry weather waste waters entering treatment plants [16] presented also fluorene, phenanthrene, fluoranthene and pyrene as 
major PAHs, but naphthalene was significantly higher than for our runoff and CSOWW samples, representing 24 to $55 \%$ of the total PAH amount.

$\underline{\text { Comparison between runoff and total atmospheric fallout at Paris }}$ centre.

Atmospheric deposition of PAHs is the predominant mode of atmospheric loading to urban surface, including roofs, courtyards and streets $[15,17]$. Therefore, a comparison could be established between urban runoff and atmospheric deposition. Total atmospheric fallout (TAF) were collected by the mean of a rain gauge.

The main difference between urban runoff and TAF lays in the presence of an important level of naphthalene in the TAF, which contributed as much as $66 \%$ of the total PAHs (FIGURE 4). This high contribution of naphthalene have been already mentioned [18]. The high solubility of naphthalene $\left(31 \mathrm{mg} \cdot \mathrm{L}^{-1}\right)$ promotes its transfer into the dissolved phase during the rain event. Its short live-time in the atmosphere, estimated as $16 \mathrm{~h}$, due to photo-oxidation by light, could explained as well the low level of naphthalene in urban runoff [17]. During collection of TAF, samples were not submitted to light exposure preventing naphthalene from degradation, whereas for runoff samples degradation could have occurred because atmospheric deposits were submitted to light during the dry weather periods.

Regardless of the naphthalene content, the TAF could be considered as one of the main source of PAHs in the "Le Marais" urban runoff since phenanthrene, fluoranthene and pyrene were observed in every type of sample. In a strict sense, the atmospheric deposit cannot be considered as a primary source since primary anthropogenic sources 
of PAHs are petrol and diesel-powered cars, incineration, domestic heating sources... Previous studies $[19,20,17,18]$ attempted to identify sources using markers but they emphasised the fact that there is much similarity and overlap between profiles from different source categories. However, when phenanthrene, pyrene and fluoranthene are the major PAHs, they could be considered as markers for incineration and/or pyrolytic sources $[21,20]$. The absence of benzo[ghi]perylene in our samples would mean that road traffic is a less important source of PAHs than incineration in the "Le Marais" catchment. This point should be confirmed by collecting waste incinerator samples from the surroundings of our experimental catchment and by analysing both their PAH contents and distribution.

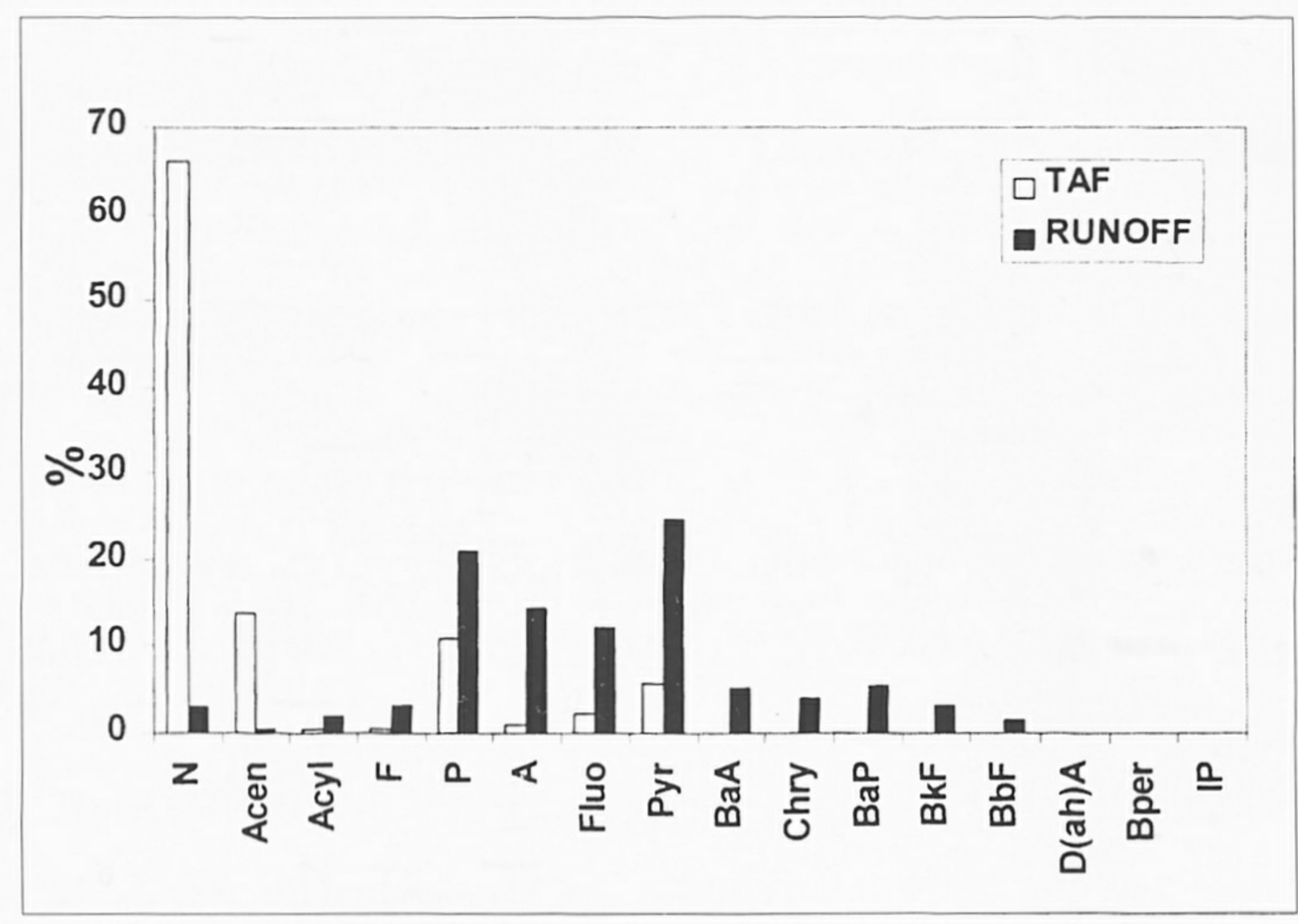

FIGURE 4 Comparison of the distribution of the total PAH between the TAF and runoff (expressed in $\%$ of the total amount). 


\section{CONCLUSIONS}

The results obtained in this study support the view that PAHs in urban samples are mainly in particulate phase and that phenanthrene, anthracene, fluoranthene and pyrene are ubiquitous. The median levels found in the different type of runoff ranged between less than $0.1 \mathrm{ng} . \mathrm{L}^{-1}$ to $215 \mathrm{ng} \cdot \mathrm{L}^{-1}$. When a "mean" runoff is considered in order to take into account the contribution of all types of runoff, the PAH level was 176 ng. $\mathrm{L}^{-1}$.

The analyses of the PAH levels for the combined sewer outlet underline the important contribution of the sewer network to PAH contamination during storm events through domestic and industrial waste waters and/or erosion of the sewer deposits. During wet weather, the median PAH amount reached the value of $204 \mathrm{ng} . \mathrm{L}^{-1}$.

The most serious, and probably the less overcome, difficulty encountered in this study was to link our results to the PAH potential sources in the urban environment. However, one of the main contribution seems to be the atmospheric fallout. This last result should be used with caution since atmospheric fallout is not a primary source. A better knowledge of the PAH primary sources would be of a great interest in order to better understand the urban PAH. For this reason, we started a research program on the identification of PAH primary sources.

\section{ACKNOWLEDGEMENTS}

Authors acknowledge the support of PIREN-Seine (CNRS GDR 1067) and "Le Marais" Experimental Urban Catchment programmes. 
Authors would like to thank as well Marie-Christine Gromaire-Mertz,

Nicole Apperry and Sonia Carpentier for their assistance during sampling and analytical campaigns.

\section{REFERENCES}

1. Chebbo G., "Solides des rejets urbains par temps de pluie: caractérisation et traçabilité.", $\mathrm{PhD}$ thesis, Ecole Nationale des Ponts et Chaussées, Paris (France): 410p + appendices (1992).

2. Gromaire-Mertz M. C., Chebbo G. and Saad M., Wat. Sci. Tech., 37 (1): 35-43 (1998).

3. Gavens A., Revitt D. M. and Ellis J. B., Hydrobiologia (91): 285-292 (1982).

4. Baumard P. and Budzinski H., Analusis, 25 : 246-252 (1997).

5. Gromaire-Mertz M. C., Garnaud S., Gonzalez A. and Chebbo G., Wat. Sci. Tech., 39 (2): 1-8 (1999).

6. Gonzalez A., Garnaud S., Carpentier S., Moilleron R. and Thévenot

D. R., Proc. $8^{\text {th }}$ international conference on urban storm drainage, Sydney (Australia), vol. 4 : 1816-1824 (1999).

7. Mc Veety B. D. and Hites R. A., Atmospheric Environment, 22 (3): 511-536 (1988).

8. Hoffman E. J. and Quinn J. G., Proc. of the "Oil in Freshwater" Conference, Edmonton (Canada) : 97-113 (1984).

9. Hoffman E. J. and Quinn J. G., Proc. of the "Oil in Freshwater" Conference, Edmonton (Canada) : 114-137 (1984). 
10. Bomboi M. T., Hernandez A., Marino F. and Hontoria E., The Sci. of the Tot. Env., $93: 465-480$ (1990).

11. Förster J., Proc. $5^{\text {th }}$ international conference on urban storm drainage, Osaka (Japan), vol. $1:$ 469-474 (1990).

12. Xanthopoulos C. and Hermann H. H., Proc. $6^{\text {th }}$ international conference on urban storm drainage, Niagara Falls, Ontario (Canada), vol. 1 : 417-422 (1993).

13. Förster J., Wat. Sci. Tech., 33 (6): 39-48 (1996).

14. Gromaire M. C., Garnaud S., Saad M. and Chebbo G., Wat. Res., submitted : 32p (1999).

15. Bomboi M. T. and Hernandez A., Wat. Res., 25 (5): 557-565 (1991).

16. Ollivon D., Garban B., Blanchard M., Teil M. J. and Chevreuil M., PIREN Seine report : 9p (1999).

17. Golomb D., Ryan D., Underhill J., Wades T. and Zemba S., Atmospheric Environment, Vol. 31 (9): 1361-1368 (1997).

18. Yang H. H., Lee W. J., Chen S. J. and Lai S. O., Journal of Hazardous Materials, 60 : 159-174 (1998).

19. Lee W. M. G., Yen S. Y. and Chen J. C., J. Environ. Sci. Health, A28 (7): 1495-1506 (1993).

20. Harrison R. M., Smith D. J. T. and Luhana L., Environ. Sci. Technol (30): 825-832 (1996).

21. Lee W.-M. G. L., Yen S.-Y. and Chen J.-C., J. Environ. Sci. Health, A28 (7): 1495-1506 (1993). 